Carla Jardim Dias

\title{
Um modelo estocástico para o fluxo de caixa de um plano de previdência de um indivíduo
}

Dissertação apresentada como requisito parcial para obtenção do grau de Mestre pelo Programa de Pós-graduação em Matemática do Departamento de Matemática da PUC-Rio

Orientador : Prof. Hélio Côrtes Vieira Lopes Co-Orientador: Prof. Luciano Vereda Oliveira 


\title{
Carla Jardim Dias
}

\section{Um modelo estocástico para o fluxo de caixa de um plano de previdência de um indivíduo}

Dissertação apresentada como requisito parcial para obtenção do grau de Mestre pelo Programa de Pós-graduação em Matemática do Departamento de Matemática do Centro Técnico Científico da PUC-Rio. Aprovada pela Comissão Examinadora abaixo assinada.

\author{
Prof. Hélio Côrtes Vieira Lopes \\ Orientador \\ Departamento de Matemática — PUC-Rio \\ Prof. Luciano Vereda Oliveira \\ Co-Orientador \\ IAPUC - PUC-Rio
}

Prof. Thomas Lewiner Departamento de Matemática — PUC-Rio

Prof. Dirce Uesu Pesco

Bolsista CNPq - PUC-Rio

Prof. Marcos Craizer

Departamento de Matemática — PUC-Rio

Prof. José Eugênio Leal

Coordenador Setorial do Centro Técnico Científico - PUC-Rio 
Todos os direitos reservados. É proibida a reprodução total ou parcial do trabalho sem autorização da universidade, do autor e do orientador.

Carla Jardim Dias

Graduou-se em Bacharelado em Matemática na UERJ(Universidade Estadual do Rio de Janeiro) em 2004 .

Ficha Catalográfica

Dias, Carla Jardim

Um modelo estocástico para o fluxo de caixa de um plano de previdência de um indivíduo / Carla Jardim Dias; orientador: Hélio Côrtes Vieira Lopes; co-orientador: Luciano Vereda Oliveira. - Rio de Janeiro : PUC-Rio, Departamento de Matemática, 2006.

v., 58 f: il. ; $29,7 \mathrm{~cm}$

1. Dissertação (mestrado) - Pontifícia Universidade Católica do Rio de Janeiro, Departamento de Matemática.

Inclui referências bibliográficas.

1. Matemática - Tese. 2. Simulação Estocástica. 3. Atuária. 4. Matemática Financeira. I. Lopes, Hélio Côrtes Vieira. II. Oliveira, Luciano Vereda. III. Pontifícia Universidade Católica do Rio de Janeiro. Departamento de Matemática. IV. Título. 


\section{Agradecimentos}

À Jesus, meu único Senhor e Salvador.

Aos professores Luciano Vereda e Hélio Lopes pela orientação, seriedade, dedicação, compreensão e paciência.

Ao meu esposo Ricardo por todo amor e paciência.

Aos meus pais Dias e Nilce e ao meu irmão Anderson pelo apoio, amor e paciência, principalmente durante meus estudos.

À Pontifícia Universidade Católica do Rio de Janeiro (PUC-Rio) pelo acolhimento.

Ao IAPUC pelo apoio e ao Icatu-Hartford pela bolsa de Mestrado.

À FINEP pelo financiamento do projeto que proporcionou a criação do laboratório utilizado no desenvolvimento desse trabalho.

Aos professores do Departamento de Matemática da PUC-Rio pelo apoio.

Ao professor Pe. Paul pelo apoio e compreensão no início do Mestrado.

Aos amigos da Puc pela ajuda, incentivo e companheirismo nesta jornada.

Às secretárias e aos auxiliares administrativos do Departamento de Matemática da PUC-Rio pelo apoio de sempre. 


\section{Resumo}

Dias, Carla Jardim ; Lopes, Hélio Côrtes Vieira; Oliveira, Luciano Vereda. Um modelo estocástico para o fluxo de caixa de um plano de previdência de um indivíduo. Rio de Janeiro, 2006. 58p. Dissertação de Mestrado - Departamento de Matemática, Pontifícia Universidade Católica do Rio de Janeiro.

O principal objetivo dessa dissertação é elaborar um modelo estocástico e implementar um simulador para a fluxo de caixa de ativos e passivos para uma simplificação de um plano de previdência privada de um único indivíduo.

\section{Palavras-chave}

Simulação Estocástica. Atuária. Matemática Financeira. 


\section{Abstract}

Dias, Carla Jardim ; Lopes, Hélio Côrtes Vieira; Oliveira, Luciano Vereda. A stochastic model for the cash flow of a retirement plan of a person. Rio de Janeiro, 2006. 58p. MsC Thesis Departament of Mathematics, Pontifícia Universidade Católica do Rio de Janeiro.

The main objective of this work is to propose a sthocastic model and to implement a simulator for the cash flow considering the assets and liabilities of a single person retirement plain.

\section{Keywords}

Stochastic Simulation. Actuary. Finance Mathematics. 


\section{Sumário}

$\begin{array}{lll}1 & \text { Introdução } & 10\end{array}$

\begin{tabular}{lll}
\hline 1.1 & Motivação & 10
\end{tabular}

$\begin{array}{lll}1.2 & \text { Objetivos } & 12\end{array}$

$\begin{array}{lll}1.3 & \text { Estrutura do trabalho } & 13\end{array}$

$\begin{array}{lll}2 & \text { Simulação estocástica } & 14\end{array}$

$2.1 \quad$ Geração de números pseudo-aleatórios 14

2.2 Geração de variáveis aleatórias 16

2.3 Geração de vetores aleatórios normais multivariados 20

3 Matemática financeira e atuarial $\quad 22$

3.1 Conceitos básicos da matemática financeira 22

3.2 Conceitos básicos da matemática atuarial 28

$\begin{array}{lll}4 & \text { O modelo econométrico } & 38\end{array}$

$\begin{array}{lll}4.1 & \text { Análise de séries temporais } & 38\end{array}$

$\begin{array}{lll}4.2 & \text { As variáveis financeiras } & 40\end{array}$

4.3 A estimativa do modelo VAR das variáveis financeiras 41

5 Um simulador estocástico para o fluxo de caixa $\quad 44$

$5.1 \quad$ Hipóteses sobre o plano de previdência 44

$\begin{array}{lll}5.2 & \text { O simulador estocástico } & 44\end{array}$

$\begin{array}{lll}5.3 & \text { Resultados da simulação } & 48\end{array}$

6 Conclusões e trabalhos futuros 54

\begin{tabular}{ll}
\hline Referências Bibliográficas & 55
\end{tabular}

$\begin{array}{lll}7 & \text { Apêndice - Dados das séries financeiras } & 56\end{array}$ 


\section{Lista de figuras}

5.1 Um cenário para a série CDI. $\quad 49$

5.2 Um cenário para a série IBOVESPA.

5.3 Um cenário para a série IGPM. $\quad 50$

5.4 Um cenário para a série SWAP. 50

5.5 Média do montante final para cada idade i. 51

5.6 Benefício inicial médio para cada idade. 52

5.7 Saldo final médio para cada idade. 52

5.8 Pagamento total médio para cada idade.

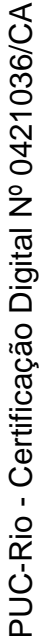




\section{Lista de tabelas}

3.1 Tábua de mortalidade AT-2000: idades entre 0 e 38 anos. 35

3.2 Tábua de mortalidade AT-2000: idades entre 39 e 78 anos. 36

3.3 Tábua de mortalidade AT-2000: idades entre 79 e 115 anos. 37

4.1 Estatísticas das séries de dados mensais de janeiro/2000 à dezembro/2005. 41

4.2 Estimação do Vetor Autoregressivo(VAR). 43

7.1 Séries financeiras nos anos de 2000 e 2001 . 56

7.2 Séries financeiras nos anos de 2002 e 2003 . 57

7.3 Séries financeiras nos anos de 2004 e 2005. 